\title{
A Practical Heuristic for Dialogical Argument-Making in Applied Ethics Rehg $\mathbf{W}^{*}$
}

Department of Philosophy, Saint Louis University, USA

*Corresponding author: Rehg W, Department of Philosophy, Saint Louis University, 3800 Lindell BIvd, St. Louis MO 63108, USA, Tel: 314-977-3827; FAX: 314-977-3696; E-mail: rehgsp@slu.edu

Received date: December 28, 2015; Accepted date: January 28, 2016; Published date: January 29, 2015

Copyright: (C2016 Rehg W. This is an open-access article distributed under the terms of the Creative Commons Attribution License, which permits unrestricted use, distribution, and reproduction in any medium, provided the original author and source are credited.

\begin{abstract}
This short communication sets forth a modification of Habermas's discourse ethics, designed to render the dialogical features of discourse ethics practically feasible in contexts that do not have the institutional resources for organizing actual discourses inclusive of all stakeholders. After briefly sketching an interpretation of Habermas's principle of dialogical universalization, I set forth a practical heuristic that recasts discourse-ethical idealizations as feasible research tasks of two sorts: dialogical argument-construction and public-merits assessment. The communication closes with a short consideration of the challenge that value conflicts pose for discourse bioethics.
\end{abstract}

Keywords: Applied ethics; Bioethics; Dialogue; Discourse ethics; Habermas; Values

\section{Introduction}

Discourse ethics first emerged in Germany in the 1970s, primarily as a neo-Kantian response to subjectivism in ethics [1,2]. Discourse ethics distinguished itself from similar initiatives of John Rawls and T. M. Scanlon by its insistence on real dialogue as an adequacy condition on moral objectivity. A moral norm is objectively valid, and thus binding on all agents, only if those agents could agree to it in a real discourse-a dialogical process of argumentation-that met idealized conditions of inclusion and reasonableness. Since its inception, discourse ethics has had its greatest impact in areas of political philosophy, above all in theories of deliberative democracy and participatory policymaking $[3,4]$. But the ambitious attempt to link counterfactual idealizations with real discourse has posed an obstacle to wider uptake in Anglophone circles [5].

In what follows I report and modify a practically usable heuristic I have proposed for a dialogical computer ethics [6]. The heuristic is designed to render discourse ethics practically usable for responsible conscience-formation in real contexts, in which the prospects of reasonable agreement are slim. My colleague and I have successfully used this model in a team-taught computer ethics course. Properly adapted, the heuristic should also work in other areas of applied ethics, such as bioethics. In that area, however, value conflicts pose an especially acute challenge, which I briefly describe in closing.

\section{Habermas's Moral Principle}

I draw the elements of the heuristic from the version of discourse ethics proposed by Jürgen Habermas [2,7]. At the heart of Habermas's discourse ethics lies a dialogical principle of moral universalization, according to which a norm of action is morally right only if all persons could accept it on the basis of good reasons (i.e., cogent arguments) after taking part in a sufficiently reasonable discourse. Like Kant, Habermas understands moral norms as unconditionally binding requirements for treating persons with due moral regard (which trump other considerations in case of conflict). And also like Kant, Habermas links moral justification with autonomy: a genuinely binding norm is one that all mature moral agents could accept on the basis of good reasons. But Habermas's dialogical moral principle ups the ante on Kant's Categorical Imperative. On a common reading, the Categorical Imperative serves as a mental exercise that helps the morally mature individual achieve an impartial moral point of view from which he or she can justify universally acceptable moral judgments. That approach, Habermas argues, fails to appreciate the subtle personal and cultural biases that infect our attempts at impartial moral justifications. Thus genuine impartiality requires us to enter into real dialogue with the people affected by our choices and moral expectations.

More fully spelled out, Habermas's principle of universalization-the so-called (U)-Principle, or (U) -sets forth the conditions for cogent moral justification:

A moral norm (social practice, policy, rule) is valid (justified and binding) only if the foreseeable consequences and side-effects of its general observance for the interests and value-orientations of each individual could be jointly accepted by all those affected without coercion [7].

This principle has come under fire, even from sympathetic readers, for its highly idealized, consensualist orientation [8]. In real moral debates, it is often difficult to determine which of the opposing views everyone could jointly accept under sufficiently reasonable conditions of discourse. In such contexts, joint acceptance is precisely what is lacking, and to project such acceptance counterfactually appears arbitrary. How then can one responsibly form one's conscience? In many situations, we do not have the luxury of withholding judgment, but (U) apparently tells us that confidence in the reasonableness of such judgments is not warranted.

These difficulties notwithstanding, Habermas's moral principle suggests a practically usable heuristic for developing moral arguments and testing their dialogical strength. On the one hand, it says something about the content of moral argument-making. As I interpret the (U)-Principle [9], a cogent moral evaluation of a problematic norm-whether existing or in prospect-must examine the implications of the norm for treating persons with due moral regard (i.e., respect). Specifically, one must ask how the norm and its observance (the 
practice) has affected or will affect the different actors' (stakeholders') pursuit of what they value ("interests and value-orientations"). This conception of cogent argument-content assumes that I can respect you as an autonomous agent only if I show due moral regard for your choices and life projects-leaving you free to make the choice in some cases, in other cases assisting you in your need.

On the other hand, the above principle also has us attend to the dialogical process of making and critically evaluating moral arguments. According to the argumentation theory that undergirds discourse ethics [10], cogent moral argumentation must be inclusive of all parties, and it must meet conditions of equal voice, freedom, sincerity, and open-mindedness (freedom from bias, judging on the merits alone). In formulating the heuristic, I reformulate these ideals of reasonableness as specific conditions on the evidence one can have for regarding one's moral arguments as persuasive-dialogically cogentand thus enjoying public merits.

\section{Feasible Dialogical Argument-Making}

The heuristic I sketch below assumes that in forming one's moral conscience, one builds an argument-content of one's own (partly by drawing on extant arguments), on the one hand, and one assesses the process and public merits of argumentation (one's own and others'), on the other. Although the latter assessment unavoidably involves personal judgment, it is not merely subjective, as it rests on analysis of objective features of the actual discussion (e.g., level of public disagreement, documentable signs of bias or bad faith in a participant) and can be challenged for failing to notice relevant developments in a discussion.

An argument is cogent at the level of content insofar as it displays due diligence in taking all the relevant considerations into account and responds convincingly to objections. Cogent content thus presupposes that one has built the argument dialogically, that is, by actively pursuing stakeholders' own statements of their values and arguments about how the practice at issue affects those values. One must therefore research stakeholder views as expressed in the various venues: in journal and magazine articles, opinion pages, online sites and blogs, and conversations. In addition, due diligence in building the analysis requires one to attend to experts on the area at issue, who might not fall into a specific stakeholder category.

At the level of process, argument cogency also depends on how that argument fares in social contexts of critical discussion that meet conditions of reasonableness [10]. Thus confidence in the quality of argument content is warranted only insofar as one can document its success, or likely success, across different stakeholder groups. To render this assessment feasible, I suggest we think of it as a comparative evaluation of the public merits of competing views. To evaluate the public merits of a position, one asks whether each stakeholder group, given its values and assumptions, does in fact, or could, reasonably accept the position/argument in question.

\section{A Practical Heuristic}

The heuristic I propose may be divided into five steps that build content, intertwined with a three-stage process of evaluating the public merits of one's own and others' arguments. The public merits assessment steps are inserted at those points relevant for gathering evidence of public merits:

\section{Step 1: Moral disclosure}

One begins by describing the morally problematic social, institutional, or corporate practice, policy, or law (hereafter simply "practice"), explaining what features raise moral qualms. This requires some understanding of the social practice at issue in its wider context; research into the topic starts at this stage. In computer ethics this stage, known as "moral disclosure," is especially necessary. Digital technologies often render social practices "morally opaque," either because users lack knowledge of the capabilities and presuppositions of many digital technologies, or because they do not readily grasp the moral implications of those technologies. The need for moral disclosure, I suspect, will probably vary according to the area of applied ethics.

\section{Step 2: Formulation of the moral question}

Similar to Kant's Categorical Imperative, discourse ethics most readily lends itself to testing social practices and norms for their moral acceptability. In teaching this method, we thus stressed the importance of articulating a well-formed question as the target of moral evaluation: Is it morally acceptable for actor $S$ to engage in social practice (law, policy, etc.)

\section{Step 3: Stakeholder analysis}

It calls for examination of the effects of a norm on all persons, or "stakeholders." Stakeholder analysis thus begins with identification of actors-more realistically, actor categories or groups of similarly situated actors-who are either directly involved in the practice at issue or are somehow affected by it. The analysis requires one to identify, for each stakeholder, the values most affected by the practice, its view of the practice and its effects, and the key assumptions that shape that view. Here "values" cover anything that structures the stakeholder's various interests, needs, responsibilities, rights, and so on.

\section{Public merits assessment, 1}

Each stakeholder group represents an audience whose acceptance is important for assessing the public merits of arguments on the issue. This assumes at least some members of the group argue in a way that displays commitment to dialogue and responsible conscienceformation.

\section{Step 4: Adjudication}

Stakeholder analysis normally reveals value conflicts, in the sense that the practice benefits some actors and harms others. To judge the moral acceptability of the practice, one must adjudicate such conflicts by evaluating the relative weight of the values at stake, seriousness of the different effects on values, and possibilities for alternative realizations of affected values. For example, one normally prioritizes consumer safety over business profits; more serious harms would call for correction more urgently than minor inconveniences; damage to a value that an actor can realize along alternative pathways is less serious than harms the actor cannot escape.

\section{Public merits assessment, 2}

Cogent argument-making aims to persuade audiences competent to judge the matter; thus one's adjudication must attempt to identify and build on stakeholders' weightier values and more plausible 
assumptions, so that one's argument may claim acceptability for those stakeholders.

\section{Step5: Judgment and possible revision}

The process of evaluation concludes with a judgment that the practice, policy, or law is or is not morally acceptable. If not, then the foregoing analysis often gives one sufficient insight to readily identify a way of modifying the practice so that it becomes acceptable.

\section{Public merits assessment, 3}

To assess public merits, one develops a map of different (reasonable) stakeholder groups and their known or likely views of one's analysis, judgment, and revision (known acceptance or rejection; likely acceptance or rejection), as compared to the merits of competing views.

\section{Responsible Conscience-Formation}

The upshot of the analysis of public merits is that we must think of cogency as a matter of degree. For determining how much confidence in a moral view is warranted, or how much of a public moral basis is available for legitimate policymaking, three levels of cogency are especially significant:

Only one of the competing views enjoys wide public merits, finding acceptance across all apparently reasonable stakeholders: that view has presumptive objective validity for all parties, and the burden of argument is on dissent

Reasonable stakeholders persist in ongoing debate, adhering to opposing positions that neither side can convincingly discredit; each of the positions thus qualifies as publicly tenable, and may be reasonably held

The debate displays a degree of contention, incivility, and distortion that precludes confidence that any opinion on the matter qualifies as publicly reasonable

If we can distinguish these different situations in practice, then we can form our moral consciences responsibly. The first position warrants considerable confidence, whereas the second requires us to mix our confidence with intellectual humility and respect for opposing views. In reaching policy decisions about a matter, greater confidence is warranted for generally acceptable positions. For tenable views, it would seem that a search for compromise is warranted, as a condition of moral regard for the reasonableness of those who disagree. In the third situation, clear-cut policy decisions lack a reliable basis; thus it is probably best to keep options open.

\section{The Problem of Values}

I offer the foregoing analysis as a model that might prove useful across different areas of applied ethics. However, one should expect that each area might require specific adaptations. For example, in areas in which business corporations are stakeholders, use of the framework presupposes clarification of what kind of moral regard we owe to businesses. Though defined as legal persons, business firms are not human beings, and presumably we do not owe them the level of moral regard we owe to human actors. In these last two sections, I want to highlight a challenge that arises for discourse ethics generally, but for bioethics with special intensity: the import of value-conflicts in moral dialogue.
Habermas draws a rather sharp distinction between moral norms, which bind all persons unconditionally, and other values that structure personal life commitments and group identity. His discourse ethics assumes that through dialogue and argument participants can eventually separate their particular value-commitments from basic moral values that support moral norms binding on all parties, regardless of particular commitments. Indeed, the counterfactual assumption of eventual consensus on moral issues presupposes that actors can make this separation and form their moral convictions accordingly. Even many sympathetic readers have found this assumption problematic $[8,11]$.

We can cast this challenge in terms of the idea of moral autonomy implicit in Habermas's discourse ethics. The (U)-Principle in effect projects an idealized process of discourse through which participants can achieve moral autonomy, in the sense of the capacity to accept and act on universally binding norms, even when those norms place constraints on their other life-commitments and values. This assumes two things: (1) that moral autonomy is a value for all participants, and (2) that autonomy stands free of-can be disentangled from-other thicker or non-moral value-commitments.

The first assumption strikes me as unavoidable for discourse ethics. If one intends to resolve moral conflicts and form one's conscience through the use of reason, then one can hardly avoid endorsing the value of moral autonomy. That value is, I take it, built into discourse ethics: the proponent of discourse ethics must accept autonomy as an essential value in contexts of moral argumentation.

But the proposed framework also assumes that morally acceptable practices show due regard for autonomous agency. At this point autonomy gets tangled up in other values, as should be clear in the adjudication stage of the heuristic, in which one must weigh values. Autonomous agents pursue diverse projects, which often conflict. The kind of claim those projects appropriately make on others-from the expectation of tolerance to the demand for others' active supportdepends on the kind of values at issue in the project. Obviously, some projects are properly constrained by others-for example, the rich man's accumulation of wealth is morally constrained by the needs of the poor at his doorstep. Indeed, the morally autonomous rich person is precisely the one who acts out of respect for that constraint.

That simple example shows that one cannot delineate the scope and demands of moral autonomy without sorting out the specific values that structure its exercise in different social practices. Presumably, participants in discourse ethics are supposed to do just that in cases of conflict. As critics point out, however, the interpretation of values is bound up with the participants' different life contexts and backgrounds. If they cannot agree on the interpretation and weight of the values at issue in a problematic practice, then we cannot expect them easily to reach agreement on the morality of that practice.

This problem is a general one for discourse ethics. But it is not a disaster, especially if we work with a more pragmatic model of public merits rather than a counterfactual projection of reasonable consensus. Consensus might or might not eventually emerge; in the meantime, we can still distinguish tenable opinions from unreasonable ones, according to the comparative level of public merits a position enjoys.

\section{Value Conflicts in Bioethics}

For discourse bioethics, values pose an especially acute challenge [12]. In bioethics we confront conflicts that turn not only on everyday 
Citation: Rehg W (2016) A Practical Heuristic for Dialogical Argument-Making in Applied Ethics. J Clin Res Bioeth 7: 260. doi: 10.4172/2155-9627.1000260

Page 4 of 4

values, but on fundamental questions regarding the meaning of human life, embodiment, genetic endowments, and the moral regard owed to non-autonomous stakeholders (fetuses, future generations, severely mentally disabled and permanently comatose patients, etc.). Once a conflict turns on different interpretations of these fundamental elements of human existence, it becomes more likely that participants in a moral debate will regard each other, not merely as holding different interpretations of values, but as holding unreasonable interpretations. That is just the sort of judgment that allows one to dismiss the other's disagreement as irrelevant in assessing the cogency of one's own view. If we allow that judgment, then each party might count its view as enjoying wide public merits, simply by disqualifying its opponent as an unreasonable judge of the values at issue. That result would misrepresent the real state of affairs, which arises from a reciprocal lack of public merits: neither side can convince the other.

Consequently, for a discourse bioethics to move forward, it must allow for the possibility that reasonable actors can reasonably disagree on fundamental elements of human existence. Traditionally, the interpretation of those elements has been the task of religion and philosophy-two areas of human life in which we expect reasonable disagreement. It follows that the analysis of public merits must acknowledge the reasonableness of groups that hold different conceptions of human existence, so long as members of the group display the signs of commitment to moral dialogue.

Beyond this modest suggestion, I suspect that the proposed heuristic can move bioethics forward only if one makes a deeper adaptation. The fundamental issues in bioethics require an expanded heuristic, which goes beyond a concern with autonomous agency (and its various projects) and says something about due moral regard for permanently damaged persons, future generations whose genetic endowment we want to change, and prenatal life. A dialogical model cannot make much headway on many bioethical questions unless it moves beyond Kant's restriction of respect to autonomous personality, and assigns levels of moral regard for wider categories of human existence.

\section{References}

1. Apel KO (1980) Towards a transformation of philosophy. Routledge, London.

2. Habermas J (1990) Moral consciousness and communicative action. MIT Press.

3. Habermas J (1996) Between facts and norms. MIT Press.

4. Webler T, Tuler S (2004) Fairness and competence in citizen participation: theoretical reflections from a case study. In GottschalkMazouz N (ed) Perspektiven der Diskursethik. Würzburg.

5. McMahon C (2000) Discourse and morality. Ethics 110: 514-536.

6. Rehg W (2015) Discourse ethics for computer ethics: a heuristic for engaged dialogical reflection. Ethics Inf Technol 17: 27-39.

7. Habermas J (1998) Inclusion of the other. MIT Press.

8. McCarthy T (1998) Legitimacy and diversity: dialectical reflections on analytical distinctions. In Rosenfeld M, Arato A (eds) Habermas on law and democracy. Berkeley.

9. Rehg W (2011) Discourse ethics. In Fultner B (ed) Jürgen Habermas. Acumen.

10. Rehg W (2013) Rhetoric, cogency, and the radically social character of persuasion: Habermas's argumentation theory revisited. Philos \& Rhet 46: 465-492.

11. Warnke G (1999) Legitimate differences. Berkeley.

12. Cooke E (2003) On the possibility of pragmatic discourse bioethics: Putnam, Habermas, and the normative logic of bioethical inquiry. J Med Philos 28: 635-653. 